\title{
Notas sobre procesos reflexivos y funciones en los nuevos especialistas de información: aproximación a los perfiles formativo e investigador
}

Conferencia inaugural del Curso académico 2000

Escola de Comunicaçoes e Artes, Universidade de Sao Paulo,

28 febrero 2000

\author{
Antonio García Gutiérrez \\ Catedrático de la Universidad de Sevilla \\ Departamento de Periodismo
}

El autor reflexiona sobre la compleja labor del documentalista, sobre los medios materiales que precisa para su labor, sobre la multidisciplinariedad que la Documentación lleva consigo, todo ello en el marco de una actividad científica. menzaré con algunas precisiones sobre el título de esta exposición y sobre sus objetivos, que tan sólo pretenden contribuir a arrojar alguna uz sobre el dilema de la transformación de la estructura curricular y sobre algunas prioridades en la investigación actual de la Información y Documentación,a saber, el eterno dilema. De los dos años de debates, en los que he participado, sobre planes de formación de comunicadores en la Universidad de Sevilla, debates a veces razonables, a veces insensatos, casi siempre interesantes, he aprendido a mirar el futuro con mayor cautela casi, como diría Edgar Morin, en términos de complejidad, a mirar las dos caras de la moneda integralmente, desde dentro y desde fuera. Esto ha incrementado mi habitual obsesión por la precisión, de un lado, pero también mis niveles de desconfianza, por otro. Intentaré transmitir en esta comunicación, si así me lo permiten, tanta dosis de la una como de la otra.

En el título se sugiere el concepto de procesos reflexivos usado en el sentido de qué debemos mirar en lo que hacemos y cómo debemos mirarlo. Crear un espacio de reflexión, desde esta perspectiva, significa promover hábitos de investigación en nuestro campo de conocimiento, la necesidad de pensarnos y describir qué rol desempeñamos y qué efectos provocamos, en suma, crear una conciencia-
} 
ción del profesional y del investigador de la información en estos tiempos de crisis identitaria. Por funciones, entiendo en qué procesos intervenimos, con qué alcance y cómo se supone que debemos hacerlo. Por otra parte, utilizo el adjetivo "nuevo" aplicado a especialistas de la información no sin cierta irritación. Lo nuevo al ser antónimo de lo viejo participa de sus mismos sentidos, queda anclado, permanentemente envejece, y quiero referirme con "nuevo" a la renovación permanente, elemento innato de un profesional de la información tan cambiante como la propia información que manipula, como las propias herramientas que utiliza, como las mentalidades de los públicos a los que sirve, en constante ebullición y transformación. El adjetivo "nuevo" debe omitirse como parte de la denominación de muchas materias de nuestras enseñanzas (por ejemplo, nuevas tecnologías); por defecto, lo que debemos transmitir es nuevo: su opuesto serán las materias retrospectivas como las historias de la tecnología o de los archivos.

La metáfora que oímos desde principios de los noventa sobre el rol y las funciones de los documentalistas creando esencialmente una escenografía y una iconología marítimas, en la que somos felices navegantes y aparecen imaginarios anclas, faros que iluminan el rumbo hacia una aventura plagada de erotismo nautico (uso el eros en el sentido de lo deseado y también del emergente mito de la red como juego) está determinando algunos debates ingenuos sobre la figura, en intensidad y extensión, de nuestros profesionales. Sin embargo, pocos hablan de las tempestades y de los naufragios que acontecen a diario en esas aguas. Sin dejarnos sucumbir por las metáforas, que siempre generalizan en exceso, prefiero ubicar al documentalista en la tierra, tierra agrícola o minera, de la que debe extraer, seleccionar, tratar y empaquetar productos culturales. Y como en la economía de mercado, el agricultor y el minero, son personajes oscuros que trabajan com herramientas rudimentarias y que dependen de un distribuidor que es quien se lleva las ganancias. Pero nuestro obrero del campo trabaja en un espacio noológico y su difusión se le escapa rápidamente de las manos, en ese aspecto estamos ante un "sem terra" del conocimiento (por más que alguna multinacional española -Telefónica- anuncie en carteles la "Terra libre" de internet, su más lucrativo sector de negocios). A pesar del desarraigo, nuestro documentalista ayudará a otros a construir miles de textos y a formar o deformar miles de mentes.

Una primera necesidad del reciclaje viene sugerida por las nuevas apariencias que adopta la información: el hipertexto ha transformado radicalmente, en una década, el concepto milenario de biblioteca. Como dice Rodríguez de las Heras, se ha producido un descuadernamiento del libro; y se han arrojado sus párrafos al viento. Esta fragmentación impone nuevos hábitos por parte de los usuarios y, en consecuencia, un nuevo espacio de reflexión y acción para nuestra disciplina.

El trabajo del documentalista esta descontextualizado pero esto no es sólo una cuestión de paradigmas aunque desde fuera, y siempre a posteriori, construyamos grandes modelos referenciales para darle cobertura. Lo que hoy es nuestra 
disciplina (a la que eludo llamar, siempre que puedo, de la misma forma y para contentar a todos acudo a la generosa anáfora) se lo debe al positivismo salvaje de Paul Otlet, el fundador belga, llamándola Documentación y usando otras etiquetas sobradamente conocidas. Pero en la época que se formó la personalidad de Otlet (último cuarto del XIX) estaba de moda ser positivista: el maquinismo se encontraba en su apogeo, el Oeste era la riqueza y la aventura, territorios siempre dominables por el pensamiento occidental libre y liberalizador, Darwin explicándonos, por fin, de dónde venimos, en suma, "orden y progreso". Ahora el optimismo positivista sobre la información se ha tornado en una pesimista actitud típica de la posmodernidad y en parte, en una dejación de lo que es nuestra responsabilidad ya completamente en manos de las máquinas, o mejor, de quienes las crean: la industria informática y de telecomunicaciones.

En nuestro campo, como en los cercanos de la Comunicación y los Estudios culturales, hemos observado, como consecuencia del positivismo optimista y paternal un cierto vértigo epistemológico, el pánico al salto, a la alternativa, que ha bloqueado el pensamiento informatológico abandonándolo en los brazos de la tecnología salvadora. Como reacción, tal vez, ha surgido en el otro extremo del péndulo un hedonismo epistemológico, la recreación o placer del pensamiento por el pensamiento, también contribuyendo en poco al desarrollo de nuestra disciplina. La reflexión y la acción, en nuestro área de conocimiento, no se han centrado ni enraizado sólidamente en un paradigma científico general en el sentido que propone Khun, a no ser por un inconsciente positivismo. Podríamos decir que tenemos una cierta adicción al modelo "victoria regia" o al picoteo y a la dispersión epistémica. Esto ha provocado constantes flirteos con disciplinas (Estadística, Computación, Linguística, Cognitivismo, Comunicación, Sociología y otras) y escoramientos hacia modas conceptuales: recuperación de información, gestión de información, análisis documental ...faltando un verdadero modelo estable e integrador de la disciplina. Como consecuencia, el frente de nuestro conocimiento no se corresponde con la altura de los tiempos, con el desarrollo tecnológico. Apenas estamos en la retaguardia.

Pero no teman que no voy a divagar sobre posmodernidad (aunque, para algunos, posmoderna es la Ciencia de la Información) y las relaciones de éstas con la información. Por el contrario, quienes mantienen ese debate como único o central de nuestra disciplina, poco han entendido sus objetivos. Ahora bien, parece necesario hacer una breve parada para desentrañar, mediante esas esquematizaciones, que son los modelos teóricos, de dónde venimos y dónde estamos, esencialmente para imaginar el camino: la ciencia moderna se está quedando en pura hipótesis.

Podemos hablar de un modelo conservacionista de la información, arrastrado desde la biblioteconomía y los archivos y que sobrevive en esos universos y también en el nuestro, en el que prevalece el soporte sobre el contenido, y 
predominan conceptos como adquisición, política de préstamos y descripciones formalistas altamente normalizadas. Si alguna entente global ha ocurrido en el mundo de la información ha sido en el seno de este modelo.

En España, como en otros países latinos, la entronización de nuevas formas de pensar estos procesos y la ruptura con la tradición provino de la concepción otletiana a través de una de nuestras rutas naturales de invasiones: Francia. A finales de los años cincuenta, junto a los primeros trabajos de Gardin, que infelizmente tienen muy poca influencia en la bibliografía documentológica europea, se crea una corriente nueva en torno a la documentación de la mano de Marcel Van Dijk y George Van Slype (también belgas como el fundador) y que culminó com una obra de excepcional importancia para los estudios documentales: "Los servicios de documentación frente a la explosión de la información". Este trabajo, traducido al español, en Argentina, en 1972 (lo que supuso la entrada y asentamiento de esa corriente en el país fraternal), se vió seguido por otros muchos en la misma línea, especialmente por la prolífica y divulgadorabibliografía de Jacques Chaumier, consultor y profesor francés ligado al Bureau Van Dijk y al sector tecnológico.

Estos últimos elementos son claves para entender cómo formamos a nuestros documentalistas e investigadores de la información en España y en parte de Europa desde hace veinticinco años y qué criterios han determinado las políticas y las ayudas a la investigación de la información en la Unión europea. Podríamos llamar a esta tácita superestructura como modelo empresarial o economicista (incluso preferimos usar el término organigrama mejor que el de modelo) basado en la división del trabajo, sujeto a la economía de mercado y a los dictados de la competitividad. La propia denominación "cadena documental" expresa tanto la partición como la sucesión de operaciones (producción, gestión y consumo de información). Los nombres de los eslabones de esta "cadena" han constituido, aparentemente sin mayor debate previo, las denominaciones de materias obligatorias de los curricula en las facultades españolas de Biblioteconomía y Documentación. A mi juicio, el resultado no ha podido ser más catastrófico: se solapan las materias por falta de definición de contenidos, durante quince años se ha forzado la maquinaria del doctorado, no concediéndose suficiente tiempo a la reflexión debido a la urgencia de ocupar plazas docentes creadas irracionalmente en las varias decenas de centros superiores de formación, los egresados son especialistas en software y en normas Fiab o Iso pero desconocen absolutamente las claves de producción y las formas de representación habituales en los discursos sobre los que han de operar. Y una nota curiosa, este modelo utiliza un metalenguaje escasamente definido, como el popular, entre los profesionales, concepto de indización o indexación que proclama, todavía hoy, todo un himno a la ambigüedad o, en su acepción empírica, niega las operaciones de análisis (lectura, captación) en beneficio de la representación (indización por descriptores, por materias, por 
unitérminos) cerrando un complejo proceso cognitivo con unas pocas operaciones simples y mecánicas.

Con la creación de la materia "Documentación" en los planes de estudios de comunicadores y periodistas en la Universidad Complutense de Madrid, en 1976, se había abierto un importante espacio académico para el abordaje de nuestro objeto, desde otras aproximaciones, en España. El contexto de los estudios de Documentación en una Facultad de Comunicación generó dos nuevos modelos: uno influido por la Semiótica al comparar el documento al signo linguístico y desmontarlo en cuatro niveles, dos formales y dos de contenido provocándose, con ello, una pérdida del sentido real de la disciplina por lo que fue rápidamente relegado, a pesar del enriquecimiento aportado a nuestros estudios, y un segundo modelo comunicacional, basado en el paradigma matemático de Shannon y Weaver recortado y aplicado al proceso documental en un excelente trabajo del canadiense Jean de Bonville que abrió nuevas sendas a pesar de su también excesivo mecanicismo.

Muy al margen de los aciertos y fracasos de una investigación incipiente y escasa y ajenos al debate académico, la creación de centros universitarios para la formación de documentalistas (reproduciendo los mismos errores estructurales de las Facultades de Comunicación), y paradójicamente desde la misma academia, iba a toda vela en la España de los ochenta. Cientos de profesionales especialistas en normas y versiones obsoletas de sofware de gestión documental egresaban anualmente en busca de discurso sobre el cual aplicarlas. A su vez, el pensamiento científico era escaso, inconexo, contradictorio, en una permanente busca de anclaje epistemológico. En este marco de desorientación, y aquí comienzan los interrogantes de esta exposición, ¿Confiarán y delegarán los productores y usuarios de esos discursos complejos de la ciencia, la cultura o el arte, en esos generalistas?

\section{Usos documentales. Algunas certidumbres}

La perspectiva pragmática de la Documentación nos ha enseñado, desde hace tiempo, empleando una afirmación tan radical como cierta que no existe documentación sino usos documentales. Este principio constituye un objetivo prioritario en una aproximación cognitivista a la formulación y resolución de los problemas que surgen en nuestra disciplina. La modelización de usuarios es una tarea de primera instancia que ha reducido su presencia, en los estudios documentales, al área de evaluación de sistemas y a algunos escasos aunque interesantes estudios de usuario en el sentido que propugnamos. El uso determina el significado, como diría Wittgenstein, y en nuestras prácticas: el usuario dice qué es relevante en documentación; al final todo se reduce a una cuestión de relevancia. Pero el usuario nos interesa también como ecuación de demandas, es decir, como observable construido empíricamente, mediante parámetros temáticos y modales, que debe ser trasladado a los cuestionarios de análisis: este asunto se podría 
resumir en dos preguntas básicas que podemos hacernos antes de proyectar un sistema de información: qué cosas piden y, sobre todo, cómo las piden.

Ante estas dos situaciones, la documentación actual responde rudimentariamente: el documentalista no ofrece la información que debe (o quiere) sino la que puede, es decir la que le permite y en los formatos que le permiten los tecnólogos. Pero, ¿Suelen preguntarse, a su vez, Ingenieros e informáticos, que desean sus usuarios/clientes doocumentalistas? ¿Nos piensan, nos intuyen, les preocupamos? Y por otro lado, ¿Sabemos los documentalistas lo que queremos, qué herramientas necesitamos, cómo pedirlas sin complejos o si son posibles de construir en la década de la llegada a Marte?

La planificación de un sistema de información exige un conocimiento profundo del usuario como sumatoria de todas las tipologías posibles de búsqueda, del dominio por parte del documentalista de las claves del discurso en que opera. Únicamente de esa forma el documentalista podrá simular el comportamiento de los usuarios del sistema, auténtico núcleo de su ejercicio profesional: aún sin saberlo, somos lectores delegados, debemos leer y representar con los mismos criterios que lo harían nuestros usuarios.

Las metodologías documentales sólo pueden abordarse desde aplicaciones discursivas, es decir, la pragmática impone pensar la documentación desde los usos. En mi caso, llevo veinte años haciéndolo en el campo del discurso periodístico, universo sin grandes complicaciones en la estructura textual pero con multitud de variables en constante transformación que constribuyen a provocar inestabilidad en el pensamiento del investigador y un permanente estado de alerta. Los esquemas heredados de las áreas científicas sirvieron de poco, más bien bloquearon los avances en este área de la organización y la transferencia de cultura actualidad y formación de conciencias. Desde hace poco tiempo hemos independizado los estudios de documentacion periodística de las aplicaciones científicas y del mismo modo deberán hacerlo otras aplicaciones como el arte y la estética.

Nuestros hipotéticos usuarios: periodistas, realizadores, fotógrafos, locutores, en suma, todos los profesionales de la Industria periodística y cultural, piden de manera anárquica, dispersa, urgente, desnivelada, mal expresada. Esto sólo incita a la crítica por parte de los documentalistas pero, reflexionando un poco, reparamos la injusticia: en efecto, esos modos que nos pueden desagradar son elementos claves del discurso que construyen y desean recuperar: !!están en todo su derecho!! Primer plano de un nino africano con una mosca en la cara que sugiera la mala conciencia occidental, imágenes de soledad, agobio, amor, saturación (la avenida Rebouças de Sao Paulo en rush...), inferencias, referencias, verificaciones, comparaciones, datos puntuales, citas textuales, el presidente sentado, bajando, subiendo, riendo, llorando, sonidos que asusten, que alegren, que incomoden, cómo, cuando y por qué ocurrió...Estas son formas normales de pedir información. 
Entonces, la pregunta es ¿estamos capacitados para responder? ¿Qué sistema necesitamos para procesar los datos y darles un adecuado formato de salida? ¿Es posible su construcción actualmente? ¿Qué tipo de interfaz precisamos?Evidentemente, el documentalista no está formado para abordar en solitario estas cuestiones porque, entre otras cosas, una de las características que exigen los actuales sistemas de información es el trabajo en red, la inteligencia compartida, el grupo multidisciplinar. Fijar las convergencias con esas otras disciplinas en el contexto de los sistemas de información es una prioridad de la investigación en nuestro campo.

\section{Fiabilidad}

La documentación se ha caracterizado, en su corta vida como disciplina científica, por un bajo nivel en su propia cultura de investigación. Bibliotecarios y documentalistas operan sobre complejos discursos sin conocer los mecanismos de estos, ni la estructura, alcance y fiabilidad de los métodos e instrumentos que usan, si lo hacen, y sin preocuparse demasiado por las consecuencias negativas de sus prácticas. Y el hecho es que la materia prima sobre la que trabajan es el texto, en todas sus dimensiones y tipos pero que, en realidad, interesa más como medio y soporte que como mensaje; manejan complicados lenguajes aparentemente incuestionables (clasificaciones, tesauros y otras estructuras teóricas extrañas para el discurso real y sus usuarios) o, en todo caso, no están preparados para cuestionarlos y destriparlos; finalmente, ejercen una poderosa influencia sobre amplios públicos anónimos sin posibilidad de retroalimentación. La responsabilidad derivada del trabajo del especialista de la información es inmensa.

Desde la incipiente actividad lectora, pues el documentalista es ante todo un lector, basada en criterios meramente formalistas, y como afirman muchos cognitivistas: el conocimiento es inseparable del modo lector, todo el proceso está repleto de lagunas, de inexpugnables e inexplicables actuaciones. De la operación de captación de una proposición del texto o imagen hasta la transformación en etiquetas manipulables en los procedimientos de recuperación el proceso documental es un totum revolutum, una incógnita, cuestión de fe, el más allá... Sin embargo, cuando consideramos todas esas acciones como objeto de observación científica, al estudioso no se le puede escapar una primera estimación: nada es verificable en las prácticas documentales. Si esto es así, como demuestra el hecho de que no seríamos capaces de reproducir el camino seguido por el documentalista en su actuación analítico-sintética podemos concluir que la documentación como proceso y como producto no es confiable. Y si no nos dejaríamos tocar la dentadura por un sacamuelas sin título ni cualificación, ¿Por que habríamos de dejarnos deteriorar la mente o manipular la información que recibimos de oscuros personajes que no son capaces de realizar un ejercicio de autoevaluación, de 
sentirse con la formación crítica suficiente para cuestionar tecnoherramientas cognitivas y complejos procesos de información?

La Universidad debe ofrecer a la sociedad un activista en la cultura de la información, un especialista reciclado a partir, pero guardando la esencia, de aquel viejo bibliotecario sabio, ilustrado, conocedor de su biblioteca y de la psicología de los lectores que a ellas se acercaban. Las cosas han cambiado y, sin embargo, seguimos siendo los mismos. Usamos nuevos términos para ancestrales conceptos. Vagamos de un lado al otro del péndulo epistemológico.

Desde el punto de vista científico tradicional, solamente alcanzaremos cotas de confianza y certidumbre si conseguimos recorrer el camino seguido por los especialistas de la información en los procedimientos y en los productos que obtienen y nos ofertan. Aún si estuvieran equivocados, porque no se trata aquí, a estas alturas de la crisis epistemológica universal, de la crisis de la crisis, de la crisis al cuadrado, de pensar en términos de verdad u objetividad sino de probabilidad o posibilidad. Para muchos pensadores caológicos lo que somos se lo debemos a la casualidad, al caos, a la entropía y no al orden universal como creíamos: ¿Cómo afectará esto a nuestro diligente y sistemático bibliotecario?

Tal vez ser capaz de explicitar los modos de acción sea suficiente, de momento: cómo los documentalista se acercan a los textos, cómo deciden en ellos los conceptos fundamentales, cómo construyen sobre estos las síntesis en función de los productos y servicios mencionados antes, cómo formalizan sus representaciones diversas, qué paradigmas y códigos subyacen tras los potentes objetos simbólicos y culturales que usamos y construimos los documentalistas y los usuarios. Este es el espacio que interesa a la Teoría: la descripción, hasta sus últimas consecuencias, de esas transformaciones y acciones sobre lo textual para reconocer, con lucidez, las estructuras y proponer los procedimientos y herramientas. La documentación, despues de todo, es una técnica íntima, individual. Sólo se da si hay contacto personal antrópico entre los objetos y estos artesanos que deben reproducirlos, reducirlos y, a veces, transcodificarlos. Piensen, si no, en la acción intelectual subjetiva del documentalista sobre la condensación simbólica que recoge una simple fotografía: separar lo que dice (denotaciones) de lo que sugiere (connotaciones).

$\mathrm{Y}$ el problema es que nuestros artesanos comenzaron trabajando con las manos de la intuición y su anclaje ideológico-cultural, como únicas herramientas, realizando un trabajo irrepetible, creando productos irreproducibles: ni siquiera por ellos mismos. Y así lo siguen haciendo. ¿Cómo explicar y superar, entonces, las contradicciones de este trabajo que tan sólo atiende a parámetros individuales en el territorio de la Industria de la Información, cuyo máximo exponente alcanzamos ahora con los nuevos canales de teledistribución y selfservice? $\mathrm{Y}$, sobre todo y nuevamente, ¿Cómo confiar en ese paradójico artesano cada vez más especializado en el medio y menos en el mensaje? Las herramientas que usa, además, son construidas por otros (los informáticos) a quienes ni siquiera les han sido solicitadas, 
sobre las que no tienen dominio ni conocimiento suficiente, tan sólo la consolación de esperar la nueva versión que solucione las lagunas de la precedente.

Y para los propios intereses de la Industria ¿Cómo sustituir al artesano ausente a mitad de un procedimiento? Médicos, arquitectos, hasta directores de cine, podemos comprobar que son capaces de continuar, siguiendo un método quirúrgico, un proyecto urbanístico, un guión cinematográfico, el trabajo ya comenzado. ¿Quién y cómo se puede sustituir al documentalista en un análisis de contenido o en la composición de una estructura asociativa en un tesauro? Y, finalmente, ¿Cómo conciliamos la paradoja del trabajo artesano y a la vez industrial o masivo?

Promover el pensamiento y la cultura de la curiosidad y de la investigación en este oficio es la única respuesta posible y urgente. Marcar nuestro propio espacio de acción y reflexión respecto a las ciencias que nos rodean sin que esto suponga un ejercicio inútil y absurdo de independentismo disciplinar porque tal vez, únicamente en la interdisciplinaridad, nuestro objeto de estudio encuentre su estatuto científico, su identidad. Introducir, entre los especialistas de la información el conocimiento de los discursos sobre los que actuan subvirtiendo el orden actual de prioridades en las Instituciones formativas. Formar en sus mentes una conciencia críticista, que deberán usar en función del código institucional que les impongan en la empresa. Ubicar su acción en las coordenadas globales apropiadas: hasta el último bibliotecario de una aldea africana con un punto telefónico puede transformar el pensamiento de un erudito escandinavo enganchado a la red. Recordemos a aquel modesto impresor saramaguiano que cambió un "sî" por un "no" determinando el conocimiento del pasado en "Historia del cerco de Lisboa". La parábola, extrapolada, sirve para llamar la atención sobre la responsabilidad de nuestros documentalistas.

En cuanto a la vertebración de los productos artesanos elaborados industrialmente ya tenemos el precedente en la industria agrícola: intervención humana mediante esquemas reglados en el contenido, asistencia de la máquina en la construcción y manipulación de envases. Nuestro equipo de trabajo, investigadores y doctorandos, mantiene un objetivo común: generar procedimientos de análisis y representación, aplicados al discurso cultural y periodístico ,que cumplan ciertos principios:

- prever y recoger todas las constantes y variables discursivas.

- conocimiento del usuario como sistema para reproducir sus comportamientos. Los perfiles de usuarios son asimilados vicariamente por el procedimiento de análisis y representación.

- elaborar cuestionarios tanto de análisis-representación como de construcción de lenguajes que permitan explicitar con detalle cada actuación y, por tanto, verificarla y, en su caso, continuarla o modificarla.

- crear intefaces simples para ser usados por los especialistas teniendo en cuenta el contexto de urgencia y rapidez en el que operan. 
- crear los procedimientos en un marco tecnológico y testarlo en el mismo previendo sus posibles evoluciones. Expresar necesidades informativas al tecnólogo para evitar la imposición de formatos.

- elaborar productos visibles y útiles. La reflexión aislada en nuestro área de conocimiento se ha demostrado estéril. Las herramientas deben ser pragmáticas y favorecer mecanismos de feedback. Simular procedimientos en sistemas complejos.

- Incorporar, en toda su extensión, el concepto de red, de trabajo compartido, de distribución de saberes.

Varios productos han surgido, en los último anos, de esta línea de trabajo que hemos instaurado en Sevilla: Por citar algunos: estudios del concepto y las políticas de selección desde la teoría de la decisión contribuyendo con cuestionarios que explicitan y, por tanto, ayudan a objetivar, los mecanismos selectivos; métodos que pretenden concretar una pragmática, y para algunos imposible, tipología de connotaciones en la recuperación de información de actualidad, estudio del lenguaje audiovisual del discurso periodístico para crear hojas de análisis y representación por secuencias; y procedimientos de explicitación estructural en los lenguajes documentales, acercando las estructuras teóricas de estos a la realidad discursiva de textos y usuarios, entre otros.

A pesar de estos avances concretos, creemos que nuestro mayor aprendizaje se ha dado en el compromiso que mantenemos con la vertiente social, en sentido altruista, de nuestra disciplina y de sus productos, a pesar del aprovechamiento económico o ideológico que quieran darle otros. Consideramos que la información es un derecho humano como proclama la carta de Naciones Unidas y que esto no puede quedar sólo en palabras. Tanto desde la teoría como desde la práctica de nuestros conocimientos debemos comprometernos con la promoción de la cultura de la información entre nuestros ciudadanos. En otras palabras, enseñar a descubrir pozos y a pescar en los territorios culturalmente desheredados del mundo. He aquí un nuevo compromiso con nuestra agricultura de la información ¿Cuántas cosas podrían hacer los especialistas de la información en esa dirección?

Las prioridades de la política científica y los proyectos subvencionados con millones de euros por la Unión europea indican que cuando hablamosde Sociedad de la información no nos referimos al mismo concepto. La sociedad de la información se establece como noble objetivo en el que no parecen caber los desinformados ni los analfabetos funcionales (culturales), o sea, la mayoría (entre el 60 y $80 \%$ en la UE, más del $98 \%$ en el litoral sureste mediterráneo, y ¿cuántos en América latina?). En todo caso, esas mayorías marginales sí serán objeto de atención por parte de la información comercial y electoral. Al introducir la competitividad de las herramientas tecnológicas, en lugar de investigar en la divulgación de culturas de la información y de tecnoculturas interactivas entre las pobla- 
ciones marginales, como eje esencial de las políticas científicas, se establece un criterio economicista y no social que comienza a delinear, en el espacio cultural mundial, un nuevo Tordesillas. Nuevas expresiones para viejas ambiciones. También en estos latifundios de la información debe operarse una profunda reforma agraria.

Seguramente, esta última pretensión es una llamada a la ética y a la conciencia profesional que sólo haría cambiar las prioridades de la investigación, de la formación y de las prácticas en el mundo a un reducido grupo de inconformistas. Pero, y termino con más preguntas: ¿Sólo debemos pensar en clientes y no en usuarios? y ¿Deben pertenecer estos usuarios a las élites (científicos, políticos, periodistas) que ya tienen el acceso a la información? y ¿Quién informa a los realmente desinformados? Y si no nos afecta a nosotros ¿A quién debe incumbir este derecho humano fundamental? 